the instrument. An earth-connected metal screen absorbed the charge.

Dr. Nodon's experiments also indicated that the potential of the soil depends upon the variable electrical state of the upper layers for the atmosphere, for when the

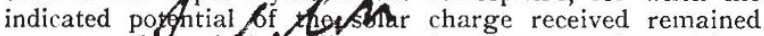
constant, thet of boil was also constant, but with a varying splut otential the terrestrial potential varied several hu hdred volts per minute, attaining its maximum when the former ceased to manifest itself. This action is much less marked at sea-level than at the altitude of the summit of the Pic du Midi. It is suggested that the rapid variations of the terrestrial potential may indicate approacining tempests, storms, and even earthquakes, and actual observations by Dr. Nodon tend to confirm this. With this method improved, prognostications of atmospheric and seismic troubles may become possible. On August $2 \mathrm{I}$, between 8 p.m. and io p.m., Dr. Nodon also detected a positive induction produced by the full moon analogous to the solar charge, and varying from one to five volts per minute.

Perth Catalogue of Standard Stars.--In "A Catalogue of 420 Standard Stars, mostly between $\mathrm{z}^{\circ}$ and $4 \mathrm{I}^{\circ}$ South Declination, for the Equinox 1905.9 0 Observations made at the Pertb Observatory Mr. W. Ernest Cook hentornment astronomer of Western Australie appears to have done an excellent piece of work, thonghtore might wish that the details had been given some at more fully.

When some of the South American observatories failed to fulfil their engagements with reference to the International Photographic Chart of the Heavens, the gap was to some extent bridged by the Perth Observatory undertaking to observe the zone $32^{\circ}-40^{\circ} \mathrm{S}$. The catalogue plates for this zone are now practically complete, but the measurement of the star images and the necessary reductions are delayed by the want of a sufficient number of known stars to furnish the plate constants. For this reason it is proposed to observe some 10,000 stars, appropriately scattered throughout the zone, and for reasons which are not explained the method of absolute determinations has been abandoned in favour of zonal observations. Unfortunately, Auwers's catalogue, which has been accepted as the basis of the system, does not contain a sufficient number of standard stars, and it has been necessary to choose others to act as secondary standards, and to observe these repeatedly. The present catalogue gives the places of 420 stars, which will be adopted as fundamental in the zone reductions.

The number of observations of each star is usually ten, and, judged by the probable error of a single observation, the accuracy of the mean result should be sufficient for the purpose.

\section{VIENNA MEETING OF THE IRON AND STEEL INSTITUTE.}

THE autumn meeting of the Iron and Steel Institute was held in Vienna on September 2/3 and 24, under the presidency of Sir Hugh Bell, and w 1 argely attended, there being about $45^{\circ}$ mephers pent. The proceedings opened with addresse of elgothe by the chairman of the reception commit/ge by Minister of Agriculture and Mines as fresentive of the Austrian Government, by the Mayor 6 ovienna, and by the president of the Austrian Society of Engineers and Architects, in the building of which the meeting was held. The addresses of wclcome, which were delivered in German, having been translated by the secretary, Mr. Bcnnett H. Brough, the president, Sir Hugh Bell, responded in an eloquent German speech, and incidentally announced that the Archduke Frederick of Austria, who had acted as patron of the reception committee, had accepted honorary membership of the institute. The technical business then began.

Mr. W. Kestranek read the first paper. It recorded the progress made in the Austrian iron industry during the twenty-five years that have clapsed since the institute last met in Vienna. In 1882 Austria-Hungary produced 600,000 tons of pig iron, and the annual output has now risen to $1,900,000$ tons. The country suffers from a scarcity of coking coal. It has nevertheless been able to maintain its position among the iron-producing counuries of the world.

In the second paper read, Prof. H. Bauerman described the Erzberg of Eisenerz, the largest of the series of mineral deposits associated with the Palæozoic rocks of the eastern Alps. The raw ore averages 38.73 per cent. of iron, and the calcined ore 50.68 per cent. The ore is obtained by quarrying, the entire face of the deposit being laid out in a series of steps or terraces, fifty-eight in all, varying in height from 33 feet to 43 feet, giving a total depth of working faces of about 2000 feet. The present annual output is about $\mathrm{I}, 600,000$ tons. The mining of iron ore on the Erzberg has been carried on from very early times. Traditionally, the workings date back to the eighth century, but there are no authentic records older than A.D. $93 \mathrm{I}$.

A paper on steel and meteoric iron was read by Prof. F. Berwerth (Vienna). The paper was prepared by way of introduction to the meteorite collection of the Imperial Natural History Museum, where opportunities are afforded for the study of metcoritic iron masses under conditions unequalled elsewhere. Meteoritic falls from 615 different localities are represented in the collection by 2075 specimens, the total weight of which is $3^{\frac{1}{2}}$ tons. Of these, 232 falls are iron meteorites, weighing together more than $2 \frac{1}{2}$ tons. The author's descriptions s!ow that meteoritic iron and steelworks' steels are results of essentially similar chemical and physical causes.

Prof. J. von Ehrenwerth (Leoben) read a useful paper on the determination of the total quantity of blast-furnace gas for a given make of pig iron. The method proposed should prove of great value in view of the increasing importance of the waste gases as an economic factor in iron smelting, more particularly since their successful application in driving gas-engines makes it necessary that closer control should be exercised in their disposal.

At the present time there is a constantly increasing number of cases in which industrial practice is profiting by the application of the laws of modern physical chemistry. Some examples of conclusions dealing with the metallurgy of iron which may be arrived at in this way were given in a lengthy paper contributed by Baron H. von Jüptner (Vienna). He dealt more particularly with the laws of chemical equilibrium as applied to metallurgical chemical processes.

In a paper read before the institute last May, Mr. C. E. Stromeyer (Manchester) mentioned several failures of steel plates and structures, which appeared to indicate that certain qualities of mild steel might have the property of changing their nature with age. In a supplementary paper he gave the results of further experiments. They have not revealed a test which will discriminate between trustworthy and treacherous qualities of steel, but they have nevertheless established the fact that mild steel does possess ageing properties, and that certain practices which are still fairly common amongst engineers are not free from dangerous possibilities.

Four papers were read on the subject of hardening steel. Mr. C. O. Bannister (London) and Mr. W. J. Lambert (Woolwich) dealt with the case-hardening of mild steel, giving the results of some observations on the microstructure of cemented bars, on the depth of hardness, and on the carbon contents. The results do not throw much light on the manner in which the carbon penetrates the metal, but the authors consider that the solid solution theory is capable of offering a satisfactory explanation. Mr. G. Shaw Scott (Birmingham) also contributed a paper on casc-hardening. He considered that nitrogen in some form is necessary for the practical performance of casehardening, and suggested that ammonia, whilst being the primc agent in any change, may lead to the formation of cyanogen, which acts as a carrier of carbon to the metal to be carburised. Nitrogen, he concluded, should be added to the list of elements which cause iron to take or retain the $\gamma$ form; and since $\gamma$ iron combines more readily with carbon than does $\alpha$ iron, the action of nitrogen on the iron would appear to be sufficient to explain its beneficial effect during the early stages of the process of case-hardening. Throughout the research burnt leather, which is in general use in trade circles in England, was employed as the standard case-hardening material.

No, I979, voL. 76] 
The results obtained in practice during the hardening of steel depend upon the conditions under which the transformations of the metal take place, and particularly on the duration and the temperature of the heating, the energy of the quenching bath, and the size of the pieces quenched. The part played by each of these factors was discussed in a lengthy paper contributed by $\mathrm{Mr}$. L. Demozay (Paris). The last paper on hardened steels, contributed by Mr. Percy Longmuir (Sheffield), was somewhat controversial in character. He stated that no metallographical investigation yet published has been of the least service as a guide to the thermal treatment of high-speed steels, and that comparatively little information has been given on the hardening or tempering of carbon steels. The diversity of structure in normal and abnormal products quenched under unsuitable conditions explains to some extent the attitude of practical men towards the microscope, but instead of leading to condemnation it should rather lead to recognition of the value of microscopical examination. Diversity indicates wasters, whilst uniformity denotes correct hardening conditions. The ideal structure, or lack of structure, of commercially hardened carbon steels is produced only in a certain range of quenching temperature, which varies according to the composition of the steel and the contour of the piece to be hardened. Temperatures outside this range result in more or less crystalline patterns, which in the smallest of sections vary from field to field. Although certain of these patterns may give the appearance of special constituents, they are in reality the product of an abnormal quenching temperature, and steels containing them, although hard, are useless for cutting or resisting abrasion.

A paper was then submitted by Mr. B. H. Thwaite (London) on the economic distribution of electric power from blast furnaces. The scheme he proposed is to pool the waste gases from all the furnaces of an iron-making district and to transmit the electrically transformed energy to a central distributing station.

The last paper submitted was by Mr. F. J. R. Carulla (Derby), who described a new blue-black paint as a protective covering for iron. In the preparation of iron and steel rods for wire drawing and galvanising, as also in the preparation of plates for tinning, the iron is kept for a time in a bath of acid to remove the scale. When hydrochloric acid is used, a solution of chloride of iron is obtained, and many methods have been devised to utilise these solutions. It is now suggested that ammonia might be employed for the precipitation of the oxide of iron, seeing that the value of the ammonium chloride is greater than that of the ammonia employed. The blue-black precipitate is a valuable addition to the list of pigments that can be employed with advantage for the protection of structural ironwork.

During and after the meeting the institute was received with lavish hospitality. The members and the ladies accompanying them were entertained at banquets by the Austrian iron trade and by the Municipality of Vienna; they were taken to luncheon on the top of the Schneeberg, to afternoon tea at the Imperial Palace of Schönbrunn, and to a special performance at the Imperial Opera House. They were honoured with a reception at Court, and the council lunched with the Archduke in his palace. On September 26 and 27 the members were divided into three groups, to visit the iron mines and works in Bohemia, Styria and Moravia, and Silesia respectively. Altogether the meeting was without doubt the most enjovable and the most instructive recorded in the institute's annals.

\section{UNIVERSITY AND EDUCATIONAL}

O INTELLIGENCE

Mr. ANDREy CaRnegie has given a donation of $10,000 l$. towards the stablishment of a technical college at

Mr. Arthur Acland is to distribute the medals and prizes of the Roy 1 College of Science in the lecture theatre of the Victor/ and Albert Museum this afternoon (October 3) at 'bour o'clock.

$$
\text { No. I } 979 \text {, voL. 76] }
$$

AT Oxford on Monday the honorary degree of Doctor of Science was confgrted upon Dr. Ludwig Mond, F.R.S., who was nomingted for the degree at the last Encænia, but was prevented by ill-health from attending then to receive it.

A course of free lectures to teachers, entitled "The Native Races of the Empire," will be given by Dr. A. C. Haddon, F.R.S., ar the Horniman Museum, on Saturday mornings from Ogtober, 1907, to May, 1908, beginning on October 12. Adminsion will be by ticket only, to be obtained from the clerk of the London County Council, County Hall, Spring Gardens, S.W.

THE mayor of the borough of Bethnal Green appeals for assistance for the Bethnal Green Free Library, which is supported entirely by voluntary subscriptions. The great want of the gresent time is a new and enlarged building in a more prominent position, to accommodate the increasing humber of readers and provide readingrooms for boys and girls. Mr. G. F. Hilcken, the librarian, will be /glad to receive donations or subscrip tions.

ANNOUNCEMENTs of the following scholarship awards have reached us :-Untiversity of London: University College-Bucknill scholarship of 135 guineas, $T$. C. Graves; entrance exhibitions of 55 guineas each, P. V. Early and B. Wrodhouse. Guy's Hospital Medical School-Senior scionce scholarships for university students, $50 l$. J. G. Sanér finior science scholarships, $150 l$., J. F. Mackenzie; 6ol., R. D. Passey. Entrance scholarships, rool., C. S. L. Roberts; $25 l$., G. D. Eccles; $25 l$., G. F. Romer.

THE programme of university extension lectures for the coming session has just been issued by the University Extension Board of the University of London. A three years' course on the evolution of mankind as seen in the development of indestries and institutions will be carried on at University College, the first term's work being taken by Prot. Lyde on geographic control of human evolution, while Dr. Slaughter will lecture in the Lent term on forms of primitive society, and Dr. Haddon in the summer term on the distribution of races. The course of work on human evolution as seen in the child and the race, brought to a successful conclusion last session, will be repeated at the Goldsmiths' College, New Cross, Dr. Chalmers Mitchell giving the earlier lectures and Dr. Slaughter and Dr. McDougall taking the later lectures.

Among recent developments connected with the Northampton (Polytechnic) Institute, London, E.C., referred to in the calendar for the session 1907-8, particular mention should be made of those in the department of technical optics. The most noteworthy of these developments is a course on the production and measurement of light, which is being given to boy day and evening students by the electrical engineering and applied physics department and by the departineta of technical chemistry jointly. The lectures and laboratory work in the electrical engineering department deal with all the various kinds of electric lamps, glow, arc, and luminescent; with the problems of the production of light, and photometry, and general questions of radiation. In the technical chemistry department the subject is taken up from the chemical side, and the whole subject of incandescent lighting dealt with. The properties of rare metals and rare earths, their production, extraction, and use for all kinds of incandescent lighting, both gas and electric, are fully dealt with, and the production of metallic filaments for electric glow lamps is thoroughly studied. In the technical optics department four new classes especially suitable for artisan students have been started. There are also special classes for the instruction of kinematograph operators, which it is hoped will place this kind of work upon a sound scientific basis.

THE calendar of University College, London, for the session 1907-8, which has just been issued, contains many new features. There is a sketch of the history of University College Dr. Carey Foster, together with a full 